\title{
Post Scripts in the Present Future: Conjuring the Post-conditions of Digital Objects
}

\author{
Aaron D. Knochel
}

When I enter "Mona Lisa" into a Google search, I get 192,000,000 results. If I limit those results to the past hour, I get 63 results. ${ }^{1}$ This is the Mona Lisa as a post-internet phenomenon: connected, in the network, impermanent, and always something more by the connections that it makes. Of course, this is not to say that the Mona Lisa has ever been a singular phenomenon, as a poststructural assessment of anything might lead to a constellation of never-ending semiotic events, where meaning shifts in and through human language. However, the never-ending semiotic events that always already create the Mona Lisa as a multiplicity have an additional character in the post-internet condition in that this semiotic terrain manifests as a visualization of what Sweeny (2013) refers to as a complex visual network. Philosopher and psychoanalyst Felix Guattari (1990/2013) comments on this growing multiplicity in 1990, coining the term post-media to refer to the convergence of television, telematics, and informatics ${ }^{2}$ :

\footnotetext{
A. D. Knochel $(\bowtie)$

Penn State School of Visual Arts, University Park, PA, USA

(C) The Author(s) 2021

K. Tavin et al. (eds.), Post-Digital, Post-Internet Art and Education, Palgrave Studies in Educational Futures, https://doi.org/10.1007/978-3-030-73770-2_6
} 
Through this transformation the classical triangulation - the expressive chain [chainon expressif], the object of reference [l'objet référé] and the meaning [signification] - will be reshaped. For instance, the electronic photo is no longer the expression of a univocal referent but the production of a reality among others. (p. 27)

To extend Guattari's speculation on the post-media is to account for the Mona Lisa as an impossible many that is searchable, ever-growing, and traceable to a myriad of meme makers and remixes. In considering the Mona Lisa in the post-internet condition, how might making and learning in art and media education respond to this moment?

Recognizing the role that network computing and software play for many in the contemporary landscape of cultural production, media saturation, and shifts in notions of literacy are paramount in understanding the future of art and media education. ${ }^{3}$ Speculating on making and learning may be aided by building on theorizations of how technological media impact contemporary artistic practice and aesthetics because of the ways that these same technologies are transforming society. Mobile computing, endless cloud data storage, wireless connectivity, and artificial intelligence have elevated the significance of how data is received and sent by the intermediaries of code, big data access, and broadband mobility. These phenomena have led to a more participatory culture of makers, enabling anyone to be an image maker, a media producer, and/or a cultural critic (Jenkins et al., 2015).

There is a good deal of ongoing work needed to understand how learning and participating in the arts in this new space of pervasive making is possible, and what it may be doing to making meaning in a social context. Recognizing antecedents in critical media education models that highlight agentic performances of the viewer in coding and decoding media are important, but might there be a need for further theorization on the role of makers in cultural production that also contemplates algorithms, connectivity, and issues of access (Buckingham, 2019)? Additionally, conceptions of the viewer and the spectator need to be understood fluidly within the role of makers so that artificial bifurcations need not dilute the many faceted nature of agency. Makers are producers and consumers of media. Art and media education might not be limited to considerations of producing and consuming media, but expand to question the capacities of data structures, network formations, and hardware configurations as the hidden curriculum in the classroom of 
the present-future. To do this critical work, this chapter reviews a range of post-theories, including post-media (Quaranta, 2013; Weibel, 2012), post-medium (Krauss, 1999; Manovich, 2001) and post-internet (Olson, 2008; Vierkant, 2010), to synthesize and advance a range of theoretical tools that may provide insight as to the immanent qualities of data and connectivity that impact making and learning in the arts. Synthesizing this range of post-theories frames a disjointed discourse of media theory relevant to art and media over the previous decade, but also questions the materiality of digital objects. Artists and educators need to consider theoretical tactics of posthumanism and education to form new trajectories in critical theory in light of a world without humans.

In what follows, I combine a theoretical argument on posthumanism and post-theories to provoke the dynamism of materiality in a postinternet condition for creative practice conjuring a future for a postconditions art and media education. First, I follow the post-conditions from post-media, post-medium, and post-internet to come to some sense of "the moment" and its possibilities. I then focus on the materiality of digital objects to theorize new opportunities for contemplating how artists working in 3D modeling and digital fabrication may offer insights into the possibility of making meaning in this moment.

\section{Conjuring This Moment of Post-conditions}

The moment in question is one that has been changed through network connectivity, mobile computing, supercomputing, machine learning, and the ubiquity of algorithms. Early twenty-first-century societies are in a technological moment that is connected historically to mass media, but the dynamics of visibility have become inverted whereby the many broadcast to the many within a closed data exchange system controlled by fewer and fewer. This is how Facebook killed the Internet (Guinness, 2015; Rovics, 2014). Perhaps this moment is typified by a treacherous assemblage of mediacide: the Internet killed newspapers (Stapp, 2019); the death of the "Old Internet" from the aughts (Notopoulos, 2019); social media erodes the potential of a shared public sphere, killing the once utopian hopes of the World Wide Web and denigrates democratic discourse (Li \& Benkredda, 2019), and your own complacency killed the Internet (Louis, 2012).

These various 'killing sprees' are all due, in part, to the fact that interactive and connected life is serviced through mechanisms of silent capital 
exchanges whereby the power of networking is free as long as you are willing to pay the price of your personal data. In a devilishly easy rearrangement of labor exchange, the attention that was so important to the function and spectacle of mass media has been replaced by a consent to data violence that is obfuscated through the lengthy consent forms users all agree to each time they start a new app or update an operating system. Labor is no longer typified by watching and listening, but by simply consenting.

In addition to the prognostication of Guattari $(1990 / 2013)$ in his use of the term post-media, other media theorists, like Domenico Quaranta (2013), have proclaimed a post-media era of cultural production. Software is the inheritor of the television, of radio, and of the printing press in reorganizing knowledge flows and creation making all things digital. Quaranta (2013) sees the post-media reference as a (possibly) tired extension of the circularity of 'post' arguments in aesthetics that typified the closing of the last century. However, similar to theorizations of postinternet (Olson, 2011), Quaranta finds the term to have value in that post-media might still be redeemable as a place of departure as opposed to a destination. While Quaranta critiques the eremitic qualities that Guattari forecasts, he does suggest that post-media may be a way to redeem new media art as a reframing away from its valorization of technology and instead as invested in the material specificity of ideation and modes of expression possible in the contemporary moment, which heavily include media technologies (2013). Post-media focuses on the

end of the consensual era of mass-media [implying] the decline of the mass media used by the powers that be to maintain consensus, in favor of a grass-roots use of the media as a tool for activists and political and cultural movements. (p. 200)

In this sense, post-media is like an empty cartoon thought bubble that marks the shared trauma of mass media psychic-labor relationships between producers and consumers, but not quite able to articulate the stammering moment of the next utterance of what this technoparticipatory-labor will mean into the future.

In Quaranta's (2013) argumentation, the usefulness of post-media as a point of generation relies on the double entendre of the term media, as both a broad reference to the mass communication systems that have marked the twentieth and twenty-first centuries and the somewhat more 
art-centric notion of media as the materials by which art is made. This double entendre is seemingly absent from post-internet discourse and a distinguishing factor between these discourses. For critics such as Rosalind Krauss (1999) or Lev Manovich (2001), there has been much more pointed use of the term post-medium to highlight this second connotation of the term media. Manovich (2001), for example, argues for a post-media aesthetics that considers the ill-fitting assessment of mediumcentric critique to address the expanding making practices brought on by computer technologies not because there is a need for more categories (i.e. net art, interactive art, etc.), but because these proliferations only assert further the inadequacies of these designations in the first place. Since the 1960s, the proliferation of forms of art practice and objects and the convergence of these types with popular forms of expression, have destabilized canonical classifications that once allowed tidier assessments of what painters do, what sculptors do, and what printmakers do. Instead, Manovich suggests conceptualizing mediums as software, in that

thinking of culture, media and individual cultural works as software allows us to focus on the operations (called in actual software applications "commands") that are available to the user. The emphasis shifts on user's capabilities and user's behavior. Rather than using the concept of medium we may use the concept of software to talk about past media, i.e., to ask about what kind of user's information operations a particular medium allows for. (p. 7, italics in the original).

When a painting becomes an interface then you are in the post-medium. Artist-curator Peter Weibel (2012) also takes up this discussion reflecting on the retroactive qualities that new media has on old media, stating "new media were not only a new branch on the tree of art but actually transformed the tree of art itself" (para. 20). Weibel makes a case that the computer and digitalization (what he broadly refers to as the media) has mutated all art forms all the way down so that the idiosyncratic characteristics of a particular medium, say the flow of paint or the patina of bronze, is "more or less over" (para. 29), and

consequently, this state of current art practice is best referred to as the post-media condition, because no single medium is dominant any longer; instead, all of the different media influence and determine each other. The 
set of all media forms a universal self-contained medium. This is the postmedia condition of the world of the media in the practice of the arts today. (para. 33)

Perhaps this is a moment that is important to reflect on: there is only postmedia and everything is subsumed into a post-medium. While there is an expanding horizon of creative practice, there is concurrently a leveling effect that makes media indistinguishable from art, and vice versa.

The leveling effect theorized in post-media and mediums is accounted for in the post-internet condition by the network ontology of current technological systems that is transposed to all forms of art. A postinternet condition is an ontology after the Internet manifested by the totalizing effect of network connectivity. Indeed, as artist Marisa Olson (2011) states "The notion of the post-internet encapsulates and transports network conditions and their critical awareness as such, even so far as to transcend the internet" (p. 61). In the post-internet condition, there is a sense that the Internet, the combination of communicating computers in a decentralized network formation that spawned decades of multimedia exchange, is the post-medium in question: an all-encoding, digital media extravaganza that can possibly take into account any and all art, even art that came before (Olson, 2008). From this position there is also a chronology that is advanced, in that there is no longer a posttwentieth-century mass media as the field of cultivation for the possible but moving into what may be possible in the almost-future of the twentyfirst century after the Internet. As Tavin and Tervo (2018) put it, "Within the contested milieu of post-conditions, the Now becomes best understood via its afterness: We have come to an end of what once was, dwelling on the potentialities of the Now" (p. 285). Perhaps the procession of time, and the reaffirmation of history as a metanarrative, suggests that the post-internet condition needs further mutation as the tendency of mediacidal consumption that hacks up the Internet in the time of Facebook, Amazon, and Google may suggest. The Internet in reference is in retreat.

Mega-corporations have so thoroughly changed online exchanges, social networking, commerce, and information exchange that it would be myopic to see the Internet in its flatness as the post-medium conceptualized as a through line of network structure and computational force that extends from the first instance of a fledging decentralized network in the Advanced Research Projects Agency Network (ARPANET) launched 
in 1969, to the development of the World Wide Web in the early 1990s, to the emergence of heavily commodified massive intranets like Google or Facebook. Certainly, the through line may be the increasing ubiquity of network connectivity and computing in everyday life, but how does one collapse vlogging, email, chat rooms, streaming, cloud computing, and online collaborative platforms into a tidy package that can be endlessly assigned to the trough of the post-medium known always already as the Internet? There is a real hazard here that this conceptualization runs the risk of doubling down on neoliberal strategies to commoditize every bit, as Josephine Berry Slater and Anthony Iles (2013) warn, "Postmedia then, cannot simply be equated with the digital convergence and networking of media: it remains instead a tactics of singularisation and subjectification immanent to capitalism's programmatic conversion of all technologies into conduits of conformity" (p. 11). In this way, a postinternet condition is undeniable for those of us living in post-industrial capitalist societies driven by knowledge economies and data connectivity. However, the current state of megacorporations colonizing online lives into their particular closed networks or what may be better described as a post-macrointranets condition will surely recede as the metanarrative of progress predicts. ${ }^{4}$ Even Facebook has to die.

Perhaps the more important question might be is there an offline and how might its post-internet condition be theorized? In a social system that is characterized by metadata, where exchanges become timestamped and registered in likes and emoticons, what may be the post-internet condition is the becoming social of the art object or the reconciliation of the network ontology of all things. As artist Artie Vierkant (2010) asserts, "Post-Internet objects and images are developed with concern to their particular materiality as well as their vast variety of methods of presentation and dissemination" (p. 1). When art becomes social, it is this very connective elasticity that makes it such: responsive, interactive, and mutable. However, the character of this mutability changes when pathways of mutation may be mapped, or pinged, so that their very definition may be determined through the distributed networks of electronic information that is the character of a current dominant form of communication: social media. An artwork, then, is post-internet when pathways by which it is connected are articulated. To put it another way, the symptoms of the post-internet condition appear within worlds of data where perception of the work as changing is through its connectivity. 
This perception is not just for the spectator, but for the maker as well. Post-internet art is not just about the uncertainty of the terrain of meaning, but the uncertainty of the thing itself. Post-internet art is really about the status of matter. It is a time of living in a set of relations that are material that need to afford the immaterial their due weight to impact life. The most prominent of these movements of giving weight has to be digital materiality: a concerted conceptual effort to give matter to the translation of life into the binary code of $1 \mathrm{~s}$ and $0 \mathrm{~s}$. In the following, I focus on the matter of digital objects to contemplate the impacts of conjuring this moment.

\section{Per(form)ing the Matter of Digital Objects}

The status of the object has changed pretty dramatically in the postconditions. Object-oriented philosophies have helped to cast a light on things (Bennett, 2010; Malafouris, 2013), objects (Bryant 2011; Harman, 2002), actants (Latour, 2005), and aliens (Bogust, 2012; Salter, 2015 ) as they act in the social and cultural sphere. Asserting this sort of autonomy to things/objects/actants/aliens ( $\mathrm{t} / \mathrm{o} / \mathrm{a} / \mathrm{a})$ is also a focus on the symmetry of humans and nonhumans within social and ecological formations, or what is called variously a social ontology (DeLanda, 2002); the mesh (Morton, 2012), and co-figuration (Knochel, 2017). In a social ontology, agency is ascribed to both humans and nonhumans as mediators in a flattened topology, and my interest in this ontological perspective aligns with what Fenwick et al. (2011) call sociomaterial approaches to education research and in particular developing curriculum for critical digital makers (Knochel \& Patton, 2015; Patton \& Knochel, 2017).

Discourses of $\mathrm{t} / \mathrm{o} / \mathrm{a} / \mathrm{a}$ often compel considerations of materiality of digital objects. How might the digital produce material realities? How do digital objects sustain durable material relationships to engender and/or encumber ontological assemblages? I've previously argued against the material cynicism ${ }^{5}$ focused on digital making, and advocated for engaging the materiality of data-bodies in art education and curriculum theory (Knochel, 2018; Knochel \& Patton, 2015). I'd like to pursue further the digital object within this network ontology by considering what I have referred to as per(form)ing.

The importance of this focus is to extend further the speculation of what makes post-internet art different, or notable as something new for 
consideration. Afterall, there have been previous movements in new media that focused on the Internet, such as net art, but it is precisely the nature of digital objects to move on- and offline that makes it distinct to this moment (Vierkant, 2010). This on/offline fluidity is implicit to the logic of per(form)ing in that form takes on an immanent quality that is forever realized in intensive and extensive properties. Per(form)ing is an ideation rooted in prototyping. Making is iterative, and through iteration there emerge instantiations of virtual potential. Per(form)ing ponders the implications of thinking digitally as an unfolding of virtual potential. Necessarily, digital codification reduces representations as encoded in numbers, $1 \mathrm{~s}$ and $0 \mathrm{~s}$, but how might infinite potential remain while still becoming one instance of an artifact. Likewise, per(form)ing articulates a relation between the matter of objects and their numerical aspects in spatial relation or more accurately how form is translated into the slice. The logic of the slice is dominant in translating 3D objects through workflows of on- and offline manifestations. Per(form)ing is not the rigidity of schemas that can be found in technical drawing as predefined points of object mapping, but rather form as an algorithm.

Important to per(form)ing thought as both procedure and creation is the concept of the "numbering number" (Deleuze \& Guattari, $1980 / 1987$, p. 389). For Deleuze and Guattari, "numbered numbers" count and codify quantity. Numbered numbers are designed objects such as machine parts or buildings expressed in geometric relation that is prescribed by measurement, gravity, and physics. Numbering numbers represent a conceptual shift that maintains the quantitative difference between numerical values while also asserting a qualitative difference achieved in infinite variation. Numbering numbers are the quantities suspended in iterative design cycles and expressed in the extensive properties of prototypes. The numbering number as multiplicity is a number concept that can support the quantitative nature of per(form)ing as immanent in the digital object as a computational material. Numbering numbers express the object as an assemblage of material and ideational possibility, and the object itself becomes a software of intensive potential with infinite extensive realizations.

One way to conceptualize the numbering number is the spatial relationships that are created through the millions of data points used to construct digital objects. Any given point is static and fixed as an entity, but multiple data points are an instantiation of the numbering number illustrating the possible expressions of reconstructing space. Consider 
Morehshin Allahyari's Material Speculation: ISIS (2015-2016) as an interesting project to think through the implications when data points are reconstituted through additive manufacturing techniques such as $3 \mathrm{D}$ printing. Material Speculation: ISIS reconstructs 12 original statues from the Roman period city of Hatra and Assyrian artifacts from Nineveh that were destroyed by ISIS in 2015 (https://www.morehshin.com/materialspeculation-isis/). The reconstructed artifacts are offered as $3 \mathrm{D}$ models that can be 3D printed at any scale and material. Allahyari's reconstruction process incorporated vast image records online, and 3D models are "created from dozens of still photographs...evoking the original in a scaleless, placeless version without material conditions" (Soulellis, 2016, para. 9 ). However, as soon as the figure model is printed, it becomes fixed as an extensive expression of those intensive properties. In February 2016, Rhizome included one of the digital statues, that of a figure of King Uthal, for open access so that anyone could download and print the object. From the ruins of a desecrated limestone statue, arose an infinite multitude of King Uthals raising questions of preservation and object guardianship. Allahyari's reconstructive gesture does conserve the data-bodies of these ancient artifacts, but per(form)ing holds that status of the digital object and its role in serving as cultural heritage in suspense. What instance is preserved, by whom and for whom?

A key property of the digital object that captures the role of intensive potentials in per(form)ing is scale. Scale is a set of relational dimensions that are proportional, such as a larger version of a photograph, or "a distinctive relative size, extent, or degree" (Merriam-Webster, n.d.) such as when a project is small scale. Per(form)ing scale is possible through the logic of the slice that is procedural layering of data points into slices that allows for infinitely complex 3D forms to come into definition and disseminatable form. Digital slicing is used in magnetic resonance imaging (MRI), computerized tomography (CT) scans, and 3D models prepared for $3 \mathrm{D}$ printing. What is significant about the slice is that it is scalable: each layer can be sized up as infinite variables at every data point essentially making size an intensive property of the digital object. By implication of this scalability, the digital object also is marked by its potential for accumulation or the extent to which it can per(form) as infinity via massive data storage, the infinite cloud, and supercomputing. There is no limit to how big the data can become.

As an example of per(form)ing scale consider Julien Deswaef and Matthew Plummer-Fernandez's Shiv Integer (2016) which is a bot that 
inhabits the website Thingiverse. Thingiverse is a massive online $3 \mathrm{D}$ printing community with a vast archive of user-created models from keychains to engineering parts. The bot downloads 3D models from the Thingiverse user community following Creative Commons share alike licenses, and then recombines them into random assemblages that then get posted back on Thingiverse. The user community has mixed reactions about Shiv Integer, being a bot clearly violates the Thingiverse user agreement, but it is still going strong with 651 designs posted under its user profile (https://www.thingiverse.com/shivinteger/about). ${ }^{6}$

Referring to the project, Plummer-Fernandez (2016) describes Shiv Integer as both taking cues from Dadaist readymades and chance art as well as being interested in the role of remix and copyleft author relationships that are codified by Creative Commons. For my purposes, I offer the sculptures as a capture of the potentials of scale in per(form)ing: as digital objects they may manifest on and offline with an infinite variability in size and dimension. Really the only thing that limits the hardcopy is the size of the 3D printer. In addition to the scale of the sculpture themselves, and the extent of their accumulation is totally arbitrary. In other words, the instance of the sculpture is only constrained by the hard coded limit that is a part of the assemblage algorithm, which is set and without logic, and the number of user-contributed designs that is a part of the Thingiverse archive which is $(n+1)$. Both instances of scale in Shiv Integer suggest that the object never ends, and while we can assert that the sculptures have scale they have no size.

\section{CONCLUSION}

Makers and learners in the post-internet condition have an array of tools at their disposal, but the convergence of all media into concentrated macrointranets present a problem for issues of freedom of expression and creative practice. In my review, I tried to construct a synthesis of various post-theories, including post-media, post-medium, and post-internet, in order to come to some understanding of the contemporary moment in art and technology and what it may mean for making and learning in art and media education. The post-internet condition offers a glimpse at blended material realities that aren't easily categorized as on- or offline, but are easily fragmented and infinitely searchable. These momentary glimpses which characterize this world feed assemblages implicating the social sphere and notions of self. However, within this quickly changing 
view are the potentials of the per(form)ing digital object that is unconstrained by scale offering a weird world of matter and a multiplicity of instances of the artifact unique to the digital object. Core to these instances of the digital object is a reconciliation of our networked lives as a posthuman potential for making and learning. Digital objects may allow for new understandings of material relations that aid in navigating an uncertain future.

\section{Notes}

1. Search conducted February 10, 2020 at 5:20 pm.

2. Note that Guattari in 1990 represents a generation of media theorists and poststructuralists, among them Roland Barthes (1980) and Marshall McLuhan (1964), paying attention to mass media and meaning in modern society, but I focus on Guattari here due to his particular characterization of post-media.

3. It is vital throughout my argument to resist a generalization of technological ubiquity as networked, mobile, or even screen based in that the economic drivers that allow access are profoundly driven by inequality. Even in post-industrial societies in phases of late capitalism such as the United States that seem to display a pervasive digitalization that allow consideration for a post-media era showcase dramatic inequality of access and use based upon where you live and your socioeconomic status.

4. Of course, one may read the evolution of mass media through the twentieth and twenty-first century as a story of progress, but the very real catastrophe of climate change may provide a very dramatic plot twist.

5. Material cynicism is neoluddist disapproval of digital practices in art and design contexts because they do not manifest more traditional material artefacts such as a painting or ceramic sculpture. The position adheres to romanticizing creative self-expression often ascribed to art learning in more traditional studio practices and often ignores the material forms and embodied experiences of digital practices.

6. As of February 20, 2020.

\section{REFERENCES}

Barthes, R. (1980). Camera lucida: Reflections on photography. Hill and Wang. Bennett, J. (2010). Vibrant matter: A political ecology of things. Duke University Press.

Bogust, I. (2012). Alien phenomenology or what it's like to be a thing. University of Minnesota Press. 
Bryant, L. R. (2011). The democracy of objects. Open Humanities Press.

Buckingham, D. (2019). The media education manifesto. Polity.

DeLanda, M. (2002). Intensive science and virtual philosophy. Continuum.

Deleuze, G., \& Guattari, F. (1987). A thousand plateaus: Capitalism and schizophrenia (B. Massumi, Trans.). University of Minnesota Press. (Originally published in 1980.)

Fenwick, T., Edwards, R., \& Sawchuk, P. (2011). Emerging approaches to educational research: Tracing the sociomaterial. Routledge.

Guattari, F. (2013). Towards a post-media era (A. Sebti \& C. Apprich, Trans.). In C. Apprich, J. B. Slater, A. Iles, \& O. Lerone Schultz (Eds.), Provocative alloys: A post-media anthology (pp. 26-27). PML Books (Original work published 1990).

Guinness, H. (2015, May 24). How Facebook is killing the open web. Make Use Of. https://www.makeuseof.com/tag/social-networks-apps-kil ling-open-web/.

Harman, G. (2002). Tool-being: Heidegger and the metaphysics of objects. Open Court.

Jenkins, H., Ito, M., \& Boyd, D. (2015). Participatory cultures in a networked eva: A conversation on youth, learning, commerce, and politics. Polity.

Knochel, A. (2017). Ground control to Major Tom: Satellite seeing, GPS drawing, and (outer)space. In R. Shin (Ed.), Convergence of contemporary art education, visual culture, and global civic engagement (pp. 264-277). IGI Global.

Knochel, A. (2018). An object-oriented curriculum theory for STEAM: Boundary shifters, materiality, and per(form)ing 3D thinking. International Journal of Education Through Art, 14(1), 35-48.

Knochel, A., \& Patton, R. (2015). If art education then critical digital making: Computational thinking and creative code. Studies in Art Education, 57(1), $21-38$.

Krauss, R. (1999). A voyage in the North Sea. Art in the age of the post-medium condition. Thames \& Hudson.

Latour, B. (2005). Reassembling the social: An introduction to actor-networktheory. Oxford University Press.

Li, T., \& Benkredda, B. (2019, June 21). Facebook created our culture of echo chambers-And it killed the one thing that could fix it. Quartz. https://qz. com/1648409/facebook-axed-trending-when-it-should-have-just-fixed-it/.

Louis, T. (2012, March 3). I killed the Internet. TNL.net. https://www.tnl.net/ blog/2012/03/03/i-killed-the-internet/.

Malafouris, L. (2013). How things shape the mind: A theory of material engagement. MIT Press.

Manovich, L. (2001). Post-media aesthetics. https://manovich.net/content/04projects/032-post-media-aesthetics/29_article_2001.pdf. 
McLuhan, M. (1964). Understanding media: The extensions of man. MIT Press.

Merriam-Webster. (n.d.). Scale. In Merriam-Webster.com dictionary. Retrieved February 13, 2020, from https://www.merriam-webster.com/dictionary/ scale.

Morton, T. (2012). The ecological thought. Harvard.

Notopoulos, K. (2019, December 28). The old Internet died and we watched and did nothing. BuzzFeed. https://www.buzzfeednews.com/article/katien otopoulos/how-we-killed-the-old-internet.

Olson, M. (2008, March 28). Interview with Maria Olson. We Make Money Not Art. https://we-make-money-not-art.com/how_does_one_become_marisa/.

Olson, M. (2011). Postinternet: Art after the internet. Foam Magazine, 29(1), $59-63$.

Patton, R., \& Knochel, A. (2017). Meaningful makers: Stuff, sharing and connection in STEAM curriculum. Art Education, 70(1), 36-43.

Plummer-Fernandez, M. (2016). Shiv Integer. https://www.plummerfernandez. com/shiv-integer/.

Quaranta, D. (2013). Beyond new media art (A. R. Carruthers, Trans.). Link Editions.

Rovics, D. (2014, December 24). How Facebook killed the Internet. Counter Punch. https://www.counterpunch.org/2014/12/24/how-facebook-killedthe-internet/.

Salter, C. (2015). Alien agency: Experimental encounters with art in the making. MIT Press.

Slater, J. B., \& Iles, A. (2013). Provocative alloys: An introduction. In C. Apprich, J. B. Slater, A. Iles, \& O. Lerone Schultz (Eds.), Provocative alloys: A post-media anthology (pp. 6-13). PML Books.

Soulellis, P. (2016). The distributed monument: New work from Morebshin Allahyari's 'Material Speculation' series. Rhizome. https://rhizome.org/editorial/ 2016/feb/16/morehshin-allahyari/.

Stapp, A. (2019, October 25). Google and Facebook didn't kill newspapers: The Internet did. Techdirt. https://www.techdirt.com/articles/20191024/ 13182743257 /google-facebook-didnt-kill-newspapers-internet-did.shtml.

Sweeny, R. (2013). Complex digital visual systems. Studies in Art Education, $54(3), 216-231$.

Tavin, K., \& Tervo, J. (2018). How soon is now? Post-conditions in art education. Studies in Art Education, 59(4), 282-296.

Vierkant, A. (2010). The image object post-Internet. https://jstchillin.org/artie/ pdf/The_Image_Object_Post-Internet_us.pdf.

Weibel, P. (2012, March 12). The post-media condition. Mute. https://www.met amute.org/editorial/lab/post-media-condition. 
Open Access This chapter is licensed under the terms of the Creative Commons Attribution 4.0 International License (http://creativecommons.org/licenses/ by $/ 4.0 /$ ), which permits use, sharing, adaptation, distribution and reproduction in any medium or format, as long as you give appropriate credit to the original author(s) and the source, provide a link to the Creative Commons license and indicate if changes were made.

The images or other third party material in this chapter are included in the chapter's Creative Commons license, unless indicated otherwise in a credit line to the material. If material is not included in the chapter's Creative Commons license and your intended use is not permitted by statutory regulation or exceeds the permitted use, you will need to obtain permission directly from the copyright holder.

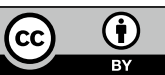

